\title{
AUTHOR(IZ)ING DEATH: Medical Aid-in-Dying and the Morality of Suicide
}

\author{
ANITA HANNIG \\ Brandeis University \\ (D) https:/ / orcid.org/0000-0003-4733-0392
}

On October 27, 2015, the Massachusetts Joint Committee on Public Health held a hearing at the State House in Boston to discuss a new bill that would enable terminally ill patients to end their life by ingesting a lethal medication prescribed by their physician. At the hearing, opponents of the proposed bill invited testimonies by those who had lost someone to suicide or who had been active in suicide-prevention organizations. That is why Pauline Mars, an elderly resident from North Grafton, got up to speak. Some forty-two years ago, her husband had shot himself in the head in their bedroom, leaving behind Mars and their four children. "On that Sunday afternoon, our lives were shattered and changed forever. I was the widow of suicide. My children were the children of suicide," she testified. "Suicide does not eliminate suffering; it causes unbearable, unending pain.” Two hours later, Mary Hoge, an elder law attorney from Medfield, warned legislators: "If you pass this law, you will redefine a tragedy and call it a medical procedure. You will call death just another choice. We all know suicide has been considered a sad consequence of depression, loneliness, fear, and desperation. Suicide of any kind is a result of a mind in turmoil, an act of a person who feels unloved and abandoned. Can we legislate love and accompaniment instead?" 
That the death of Mars's husband was unrelated to a terminal illness mattered little. For opponents of medically assisted dying, an ailing patient's underlying condition does not carry much weight — ethically or practically — in justifying what they consider an untimely exit. On the contrary, many of them locate virtue in enduring suffering at the end of life instead of taking "the easy way out." Similar to Hoge, critics consistently portray patients who pursue what they call "doctor-prescribed suicide" as plagued by undiagnosed depression or social abandonment (Golden and Zoanni 2010). They point to the danger of normalizing suicide through the passage of assisted-dying laws and voice concern about "suicide contagion." The issue goes well beyond semantics, of course. By equating a physician-assisted death with suicide, opponents argue for the moral and ethical equivalence of both.

Especially during the past decade, proponents of assisted-dying laws in the United States have become increasingly invested in drawing a robust line between medical aid-in-dying and a suicidal act. "I've devoted my career mainly to suicide prevention, but these patients aren't suicidal," Carl Brownsberger, a physician from Belmont, declared as part of the same public hearing in Boston. "They don't want to die - their death is coming down a train track toward them, and it seems like it's true reverence to life to give them some kind of control over the timing and means of their death." Right-to-die activists across the country welcomed the statement released by the American Association of Suicidology (AAS) on October 30, 2017, asserting that "suicide and physician aid-in-dying are conceptually, medically, and legally different phenomena," therefore placing medically assisted deaths as matters "outside the central focus of the AAS." ${ }^{\prime}$ For them, the statement represented a hopeful step toward shifting the terms of a public conversation that continues to conflate aid-in-dying with the terminology and morality of suicide. As Roger Kligler, a physician suing the Commonwealth of Massachusetts for his right to die, remarked to me: "Calling it suicide means that we're not talking about end-of-life issues."

This article examines the shifting rhetoric that has surrounded the legalization of a form of intentional death that is permissible in eight U.S. jurisdictions today. ${ }^{3}$ It reflects on the stakes of maintaining a discursive and conceptual distinction between a medically assisted death and the most common cultural category for self-inflicted death - suicide. Inspired by Ian Hacking's (2008, 1) observation that "the meanings of suicide itself are so protean across time and space that it is not so clear that there is one thing, suicide," this article aims to understand on what basis the differentiation between medical aid-in-dying and suicide rests, how it is upheld in practice, and what we gain and lose by insisting on it. My goal here is not to determine whether assisted dying does or does not amount to suicide. I am 
far more interested in how this debate exposes understandings of human agency, responsibility, and rationality when it comes to life-limiting illness and purposive death in the United States. What are the broader moral stakes for fighting over a division between aid-in-dying and suicide? How, exactly, is this form of death registered legally? And how does assisted dying facilitate cultural ideals of a good death that depart from quintessential notions of suicide as a bad death?

The categorical distinctions advocates invoke between medical aid-in-dying and suicide go beyond a simple search for legitimacy and an attempt to distance themselves from the societal stigma that continues to surround suicide in the United States today - although they do that too. In carving out a form of willful death that sits in a category of its own, activists can gesture to the complex medico-technical, bureaucratic, and legal assemblage that has come to govern assisted deaths and that has led to their routinization in states that permit them. As the sociologist of law Shai Lavi $(2005,3)$ notes: "Suicide is always an extraordinary act performed under extraordinary circumstances, whereas the medical hastening of death is meant to be a routinized response to a problem we all know we may face, the onset of a fatal illness." By stressing the role of debilitating, terminal illness in an aided death and by submitting such a death to the rationale and management of institutionalized medicine, ideas about human agency undergo an interesting shift.

As much as an assisted death - similar to a suicide - has been interpreted as a radical act of free will (Callahan 2002), agency in aid-in-dying is much more diffuse. It is dispersed among a patient's illness, the institution of medicine, and the state - both discursively and in practice. This kind of agentive displacement - the idea that agency for an act ostensibly authored by a single actor comes to be distributed among a range of actors - enhances the moral and social acceptability of an assisted death, which becomes an authorized form of dying that looks very different from the socially deviant act of suicide. Although external authorization of and shared responsibility for an aided death are never fully reconciled with the idea of singular, rational authorship, exploring this tension is productive for reminding us that human agency in living and dying rarely equals autonomy (Mahmood 2001). The goal of this article, then, is to uncover the complex dialectic between authorship and authorization that characterizes medical assistance in dying and attendant moralities of intentional death, speaking to broader disciplinary concerns in the cultural study of death and medicine.

This article draws on ethnographic field research that I have conducted with physicians, patients, families, hospice workers, activists, pharmacists, religious figures, lawyers, and legislators, primarily in Oregon, Washington, and New England, 
since October of 2015. The research is ongoing and has, to date, consisted of more than eighty in-depth, personal interviews; collection of data at public hearings, court cases, death-care workshops, and volunteer trainings; archival work; as well as participant-observation during end-of-life social events, such as Death Cafés and film screenings. The project began amid ultimately unsuccessful efforts to legalize aid-in-dying in Massachusetts (in 2015 and again in 2017), and my work in this context involved following those who had a stake in this legislation, as well as those who had availed themselves of Vermont's assisted-dying law. Since then, the bulk of my research has focused on Oregon, the state with the longest experience of implementing an aid-in-dying law in the United States. I met with contacts in restaurants, coffee shops, private homes, offices, and public gardens in the greater Portland area and throughout the state. From January to August 2018, I also served as a Portland-based hospice volunteer so as to map the context in which these conversations emerged.

In setting out on this project, I was less interested in abstract debates about assisted dying than in how the practical reality of this form of death is changing the ways patients, families, and clinicians view and manage the end of life. As a result, most of my research has focused on those who administer and make use of assisted-dying laws in the United States, rather than on those who categorically oppose this practice (though their viewpoints do feature in the research as well). In wanting to document how medically assisted deaths transform the landscape of death and dying, I have identified myself as an observer sympathetic to the cause (which I am), while at the same time trying to retain the critical distance necessary for the work of analysis.

To better appreciate how aid-in-dying has been positioned against suicide as a form of intentional death, the next section revisits key approaches in the anthropological study of suicide, followed by a brief historical framing of assisted death in the broader context of the medicalization of dying. The subsequent three sections move from discussing agentive displacement onto a patient's terminal illness to agentive displacement onto the authority of the medical profession and the state to a discussion of the idea of authoring a good death. This structure exposes the question of how outside authorization through agentive displacement comes into tension with the idea of authorship, an issue taken up again in the conclusion.

\section{SUICIDE REFRAMED}

Rather than subscribing to universal definitions of suicide, anthropologists have tended to study suicide as an expansive heuristic in situated ethnographic 
contexts. In doing so, they have generally moved away from older sociological, statistical approaches that locate suicide beyond the individual in the social fabric and its attendant constraints (Durkheim 1951; Douglas 1967; Halbwachs 1978). Émile Durkheim (1951) famously attributed suicides to the level of integration of members in their society, in which both too little and too much integration could lead to suicide. While embracing the idea of suicide as a deeply social act, anthropologists have criticized Durkheim's approach as overly deterministic (Livingston 2009; Garcia 2010), pointing to the varied ways people build and sever relationships. Studying the field of suicide ethnographically has attuned anthropologists to distinctive forms of self-death that carry discrete moral valences, such as the voluntary, requested death of Chukchi elders in Siberia, which is understood as a commendable sacrifice and as a ritual inversion of ordinary suicide (Willerslev 2009).

Despite the variation in practices of self-inflicted death, the editors of a recent volume on suicide and agency identify a striking tension in vernacular and expert understandings of suicide: "the requirement for agency and a simultaneous denial or diffusion of the agency of the suicidé" (Münster and Broz 2015, 11). On the one hand, in order to be thought of as such, the act of suicide requires what they call "singular intention" (Münster and Broz 2015, 11) and relies on ideas about sole authorship; on the other hand, responsibility for the act is almost never fully attributed to the agent. As evident in both psychological and sociological approaches to suicide, there always exists an "external other" (Münster and Broz 2015, 14) mental illness or society, respectively - that diminishes or deflects the agency of the individual. ${ }^{4}$ This agentive tension, the editors point out, relates directly to the moral evaluation of suicide in a given context, as "convictions about the im/morality of suicide determine the un/ease with which agentive involvement" is perceived (Münster and Broz 2015, 19) and whether a given act is classified as suicide. ${ }^{5}$ Instead of resolving this tension, they suggest studying it ethnographically.

Whether or not we group medically assisted deaths under the rubric of suicide, the same dialectic between authorship and authorization characterizes rightto-die discourse in the United States. On the one hand, advocates position aid-indying as an act of autonomous will that hinges strongly on notions of authorship. They often invoke the language of rationality to prove lucid intent and to juxtapose aided deaths to the alleged irrationality of suicides, calling attention to the screening process of assisted-dying candidates that seeks to ensure that patients' motives for ending their life are based on a rational decision that stems from a place of physical rather than mental pathology — a decision, in other words, by a self-possessed actor intent on orchestrating their own death. On the other hand, 
we see clear instances of agentive displacement, in which agency is discursively shifted onto the patient's fatal illness as the true cause of their demise and, in practice, onto medicine and the state, which ultimately need to authorize this form of death (hence the terminology of "assistance"). An aided death cannot be achieved autonomously but depends on other actors (physicians, psychiatrists, pharmacists, hospice staff, volunteers, and family members) sanctioning, facilitating, and sharing responsibility for such a death. While human agency is not wholly evacuated in aid-in-dying, it becomes distributed among entities that have the power to affect the moral and conceptual status of assisted deaths as something other than suicide. By relocating agentive power in part to forces external to these deaths, advocates also advance the notion of a kind of nonhuman agency that resides in a pathophysiological state - the patient's terminal diagnosis. As one Oregonian patient put it: "I'm not killing myself; bone cancer is taking care of that." This type of agentive displacement highlights the fact that patients have entered a temporal space of imminence to death where their personal capacity to act has become severely curtailed. The agentive power granted to a patient's fatal illness serves to reiterate the inevitability of their demise, which in turn softens the potent onus that continues to surround the idea of causing one's own death.

Until well into the nineteenth century, suicide was considered a crime in the United States, one punishable with forfeiture of the deceased's property, denial of a Christian burial, and postmortem bodily mutilation (Lopes 2015, 42-43). Long considered a violation of nature's law of self-preservation and an affront to God, the sovereign, and society, suicide gradually came to be seen as a result of mental disorders, particularly melancholia. Although suicide (but not its assistance) has been decriminalized today, it remains heavily stigmatized. As Hacking $(2008,3)$ notes, "News of a suicide among us has an immediate response: horror." In On Suicide Bombing, Talal Asad $(2007,67)$ offers one explanation for why suicide continues to be seen as an act of deviance beyond its treatment as a mental illness: "Suicide is a sin because it is a unique act of freedom, a right that neither the religious authorities nor the nation-state allows. Today, the law requires that a prisoner condemned to death be prevented from committing suicide to escape execution; it is not death but authorized death that is called for." Suicide, Asad suggests, challenges the state's enduring monopoly over violence and death.

By equating medical aid-in-dying with suicide, opponents of the former can tap into the persistent social taboos and moral outrage that surround the lattereven if no longer primarily seen as a sin, the act of taking one's life remains strongly suspect. But even those in support of medically aided deaths generally do not 
challenge the prevalent image of suicide; they simply put aid-in-dying outside that category, thus creating a form of intentional death that is not negatively judged. Nonetheless, it would be a mistake to boil down contemporary efforts to distinguish assisted dying from suicide to the social illegitimacy and perceived abnormality of suicide. Such a reading risks reductionism as it obscures the complex processes - medical, legal, bureaucratic - through which new cultural categories develop and congeal.

\section{THE MEDICALIZATION OF DEATH}

In the United States, aid-in-dying emerged from the medicalization of death over the past two centuries as an event that could be managed, controlled, and tamed by doctors at the deathbed (Kaufman 2005). "By the end of the nineteenth century," writes Lavi $(2005,15)$, "death and dying were governed by medicine, not by religion, and the old art of dying was replaced by a medical and technical governance of death.” Even before physicians had medicines for easing the process of dying, they began caring for those close to death. As death came increasingly under the purview of bio-scientific systems of authority, it slowly migrated away from the home and into the hospital. Simultaneously, with the advent of anesthesia transforming sensibilities of suffering (Pernick 1985), notions of a painless death gained popularity. Especially for those diagnosed with painful, incurable diseases, the possibility of dying a "gentle" death became attractive and led to the introduction of two legislative proposals - the so-called chloroform bills — in Ohio and Iowa in 1906. Both bills envisioned the use of chloroform on fatally ill or injured patients to induce their death, but their terms were so flawed that they never materialized (Lopes 2015, 19-23). For the remainder of the century, no other proposals for actively expediting the death of patients proved successful. None, that is, until Oregon's 1994 Death with Dignity Act, which voters approved at the ballot box by a thin margin, prompting its legal stay until 1997, when popular support for the bill was reaffirmed. ${ }^{6}$

In Oregon, administrators and state health officials were initially split on which terminology to use to frame the emergent aid-in-dying debate. In the late 1980s and throughout the 1990s, it was not uncommon for them to use the term physician-assisted suicide, borrowing from contemporary medical and bioethics literature. "That was the terminology at the time," Katrina Hedberg, state epidemiologist at the Oregon Health Authority, recalled. "We wanted people to know what we were talking about." After the first few years and some lobbying by right-to-die activists, administrators of the law - like most lay people in Oregon-began to go with the name of the Oregon law, Death with Dignity, and dropped the term sui- 
cide. ${ }^{7}$ Today, unless they are strictly opposed to the practice or are unfamiliar with the issue, most observers and many professional organizations, such as the American College of Legal Medicine and the American Public Health Association, use a variation of the terms physician-assisted dying or medical aid-in-dying, highlighting the evolving idea of aid-in-dying as a medical procedure.

Peter Goodwin, one of the architects of the Oregon law, came to regret sticking with the language of suicide initially. Committee members that worked with him on the 1994 campaign had asked him to avoid the term suicide, because "they felt that this was not suicide. This was so different from suicide, in every parameter. And I felt that it was such a well-established phrase within the medical community that to fight against it would be in vain. . . And now I regret it tremendously. Because that is such a colored phrase." At the end of the day, the doctor claimed, assisted dying was not suicide, as it adhered to a distinct, medico-legal logic: "These are patients taking some medication, which we have prescribed according to a proposed law. I have always thought of this as a rational response to a medical problem. And it is the most - it is one of the deepest medical problems. Perhaps the deepest medical problem is how to deal rationally with terminally ill patients."

Framing a hastened death as a logical, bureaucratic response to the problem of dying leads to a defensible delineation of the practice as a form of medical treatment, rather than an act of murder or self-murder. Early proponents of assisted deaths had made a very similar argument, stressing the medical context from which these considerations arose. For them, these deaths "did not emerge primarily from a personal desire to bring one's life to an end, nor from the desire of relatives or physicians to murder the dying patient, but rather from a more calculated and institutional decision following the logic of medical practice" (Lavi 2005, 88-89). Thus what differentiates a terminally ill patient who uses a gun to end their life from one who undergoes an aided death is that an assisted death occurs within the medical care system, following medical protocol. "It's a medical process, because the medicine is prescribed," George Eighmey, a prominent right-to-die proponent, told me. "Because of that, we insisted on calling it medical.” From its inception, aid-in-dying legislation in the United States has been dedicated to following a medical model aimed at making assisted dying a routine, if rare, medical practice. In this way, discourse around medically assisted dying "does not challenge, but makes productive use of the larger framework of the medicalization of dying" (Karsoho et al. 2016, 188), requesting the involvement of clinicians and medicine at the end of life.

In the United States, clinicians have long been involved in easing the dying process for fatally ill patients under the aegis of the hospice and palliative-care 
movements that emerged in the 1960s, largely as an antidote to the excesses of life-prolonging, curative medicine (but still under a medicalized model of dying). To qualify for hospice - which in the United States typically entails in-home services rather than the move to a facility — patients must have a life expectancy of less than six months and stop any treatment that goes beyond symptom control. On hospice, patients generally receive enough medication to be comfortable. Yet in rare situations when their pain cannot be palliated, patients may request what is known as "terminal sedation," the administration of sedatives putting them into a coma that will eventually lead to death, especially if nutrition and hydration are withheld concomitantly. It is noteworthy that such forms of lethal dosing were institutionalized largely "without undergoing any legal, moral, or public scrutiny" (Lavi 2005, 127), as they are primarily understood as treatment for pain rather than the intentional termination of someone's life (and hence permissible, even in Catholic hospices). End-of-life care on hospice can thus sometimes blur into the kind of ending life care usually associated with laws like Oregon's Death with Dignity Act. ${ }^{9}$

Medicine's power to frame and manage aspects of human existence moves into clear focus here. The participation of medical professionals in aided deaths not only affords patients a key measure of social legitimacy, but it also diffuses attendant moral responsibilities for their death and increases chances for a successful outcome because of the perceived technical know-how of clinicians (see Richards 2017, 353). According to one prescribing physician in Portland, once he began offering his attendance at their deaths, nearly all his patients have taken him up on it, even though all he does is watch the patient drink the lethal medication. In Canada, where qualified aid-in-dying patients can choose between a self-administered death and a lethal injection by a clinician (an option unavailable in the United States), more than 99 percent opted for an injection between January 1 and June 30, 2017. ${ }^{10}$

Yet it is not just the authorizing power of medicine that distributes human agency when it comes to aid-in-dying. According to advocates, in the unfolding course of a patient's illness, the patient ceases to be the primary actor; instead, their terminal condition seizes agentive power.

\section{TERMINAL ILLNESS AND AGENTIVE DISPLACEMENT}

During our conversations, some advocates of assisted-dying laws would occasionally raise the issue of the so-called 9/11 jumpers - the estimated two hundred people who leaped from the World Trade Center towers that Tuesday morning in 2001 to escape the scorching heat caused by the crash of two airplanes. Or they would paint an analogous scenario of a different high-rise engulfed by deadly fire. 
Whether real or hypothetical, the general contours of the setup never changed, and neither did the expectant look on my contacts' faces when the scene was complete. To them, the example of people trapped so cruelly — no longer facing a meaningful decision between life and death, but between different forms of dying — resembled the painful predicament of patients with a terminal diagnosis pondering a physician-aided death.

It remains unclear how many of those who dropped from the Twin Towers on $9 / 11$ were pushed out by accident and how many made the deliberate choice to die from jumping rather than from being burned alive. Either way, tasked with filling out death certificates for the fallen, New York City's Office of the Chief Medical Examiner refused to categorize any of the fallen as suicides (or "jumpers"). "A 'jumper' is somebody who goes to the office in the morning knowing that they will commit suicide," a spokeswoman told reporters (Cauchon and Moore 2002). "These people were forced out by the smoke and flames or blown out." In the end, her office classified all those who had plunged to their deaths that day as homicides from the attack.

Despite requiring some mental acrobatics, the burning-building analogy that aid-in-dying advocates liked to invoke captures something fundamental about the temporal and agentive logics that undergird understandings of an assisted death in the United States. ${ }^{11}$ For proponents, medical aid-in-dying constitutes an anticipatory act that preempts an already looming, inescapable death. It accelerates a trajectory that is imminent and frequently accepted - if somewhat unknown in its exact course - and it substitutes one type of feared death for another slightly less feared one, or at least one that the patient may direct. The temporality of assisted dying is forever and anxiously oriented forward — not to a distant ending, but to a near one that the patient seeks to intercept. As one patient-advocacy organization argued in a no longer available web resource: "The patient's primary objective is not to end an otherwise open-ended span of life, but to find dignity in an already impending exit from this world. They're participating in an act to shorten the agony of their final hours, not killing themselves; cancer is killing them."

Aid-in-dying abbreviates a life expected to end in the foreseeable future; for instance, Oregon's Death with Dignity Act stipulates that patients must have a prognosis of less than six months to live. This idea of expediting an unavoidable fate surfaces prominently in the term hastening, which is how participants - until recently — would refer to an assisted death. They would say, "we're going to a hastening" or "Sally is hastening." 12 The concept implies moving up a known end point in time - dictated by a patient's terminal prognosis — rather than the active cessation 
of a life that would otherwise continue. Proponents consider the difference critical. Aid-in-dying operates according to an anticipatory calculus not of life over death, but of one kind of death over another.

The perpetual forward-looking trajectory of a preemptive death can provoke much anxiety in patients and families, particularly when it comes to correctly timing one's exit. To have the death they prefer, patients may have to sacrifice some "good" days. If patients suffering from amyotrophic lateral sclerosis (ALS), for example, wait too long, they may miss the obligatory window in which they are physically able to self-administer and ingest the medication. Most patients describe a palpable turning point that led them to make concrete plans for their death. For Nancy, who was diagnosed with ALS in March of 2008, that turning point came when she started to lose her ability to speak. By January of 2009, Nancy's life expectancy was estimated to be less than six months. At that point, she qualified for Oregon's aid-in-dying law, but she was not ready yet to take the lethal medication. "She was so strongly aware that she wanted to stay alive as long as she could, so her target time was to go into June or July," her older sister Marnie recounted. "But the progression of her speech becoming so challenged meant that she could wake up one day and not be able to swallow, and she had to be able to swallow; it's that volitional act. She felt so strongly about not wanting to be hooked up to a feeding tube, some apparatus that would be breathing for her and all that." Nancy didn't make it until June. She took the medication in April of 2009 in her backyard in North Portland.

Although patients like Nancy may choose certain parameters of their death, supporters of medical aid-in-dying emphasize the constraints of patients' agentive involvement, even as they frame their advocacy primarily in terms of enhancing people's end-of-life choices. ${ }^{13}$ Ari Gandsman (2017) points to this very paradox in his work with right-to-die activists in North America and Australia. Despite their reliance on the language of choice, Gandsman (2017, 5, 10) notes, activists "construct an ethical worldview . . . that transcends the rhetoric of freedom, choice, individualism, autonomy, and self-determination," such that "the right to die is thus a choice exercised in the context of having no choice." As in other contemporary understandings of self-inflicted death, there is a simultaneous attribution and disavowal of agentive power. Advocates argue that patients' ability for purposeful action comes to be severely constrained by their terminal illness - it is the blazing fire that pushes them to the window. "I understand that I have no choice about the fact that my life is ending," an Oregonian diagnosed with a fatal glioblastoma let his physician know. "My only choice is to determine the circumstances of my death." 
Proponents highlight the primacy of a patient's underlying terminal illness that not only drives them toward an assisted death but that is also responsible for killing them. This form of agentive displacement adds complexity to the notion that patients are killing themselves, even if they are the ones who ultimately lift the lethal drink to their lips or press down on the plunger on their feeding tube. Though Oregon law requires self-administration and therefore a certain type of agency not located in the disease, a patient's medical condition is seen to significantly diminish their agentive potential. It is in this restricted, narrow sense that we must understand the sometimes fetishized discourse around choice and autonomy that characterizes right-to-die advocacy in the United States. If the right to die represents a choice, it is an acutely limited one.

David Grube wrote his first prescription for aid-in-dying in 1999. At the time, he was part of a clinical practice in Philomath, a small Oregon town near Corvallis, where I met him in 2017 in a downtown café and again, a few days later, at his home. One experience from his early clinical years had left a particularly strong impression on Grube; he said it haunted him still. He witnessed the aftermath of a shotgun death of one of his neighbors, who also happened to be his patient. Jerry was a man in his early fifties suffering from bladder cancer that had metastasized to his bones and left him in uncontrollable pain. He had entered hospice, with his life expectancy now measured in weeks. It was on one of the doctor's days off that he got a call from Jerry's son who asked him to come over to the house, and quickly: "There's something wrong with Dad."

And it's just a couple hundred yards, so I went over to his house. The TV in the bedroom was on so loud you could hear it from the street. So I went into the room and Jerry was sitting in a chair between the twin beds in their bedroom with a shotgun in his lap and nothing above his neck - everything on the ceiling. I've never - I have, you know, I've practiced medicine for forty years, I've been in the ER, I've taken care of car accidents - this is the worst experience of my clinical practicing. It just really impacted my whole psyche. This can't ever - this is the worst way.

Jerry's death proved a turning point in Grube's career. He had no legal ways of assisting Jerry with other options to shorten his anguish, so in a way he felt that he had failed as a doctor. But if he struggled to come to terms with the gruesome manner of Jerry's death, he did not struggle to comprehend the reasons for it. Grube drew a sharp distinction between a "suicidal" person who wants to die for 
reasons related to mental illness, addiction, or unrequited love, and patients like Jerry who are facing imminent death. "These patients, they want to live," Grube said. "They want to live forever, just like I do. They do not want to die. But they're going to die. It doesn't matter what they think." Absent a terminal diagnosis, most aid-in-dying patients have no independent desire to end their life, the doctor maintained. But given the inevitable course of their illness, the choice regarding death is no longer theirs to make.

Those critical of aid-in-dying take issue precisely with the temporal and agentive logics laid out by proponents. Most of them bristle at the very idea of hastening, and they believe that even a terminal illness cannot dilute the active agency behind taking one's life, which they view unequivocally as suicide. For critics, a patient's life-limiting illness fails to constitute an agentive force. Catholic opponents of the law, in particular, argue that it is against God's design to accelerate one's demise and timeline, pointing to the redemptive potential inherent in bodily suffering and insisting that the intentional taking of a human life is always wrong (Callahan 2002; Schotsmans 2003). As James Driscoll, the executive director of the Massachusetts Catholic Conference, told legislators during the 2015 hearing on Beacon Hill: "The Catholic Church teaches that life is a gift from God and should be cherished and nurtured until natural death, not predetermined death based on a diagnosis of terminal illness." Rather than being indicative only of biological decline, terminal illness, from this vantage point, holds spiritual possibility.

Many religiously motivated opponents argue that by usurping the power of God over life and death, patients who opt for an assisted death are doing away with something that is not theirs to give up. Rushing the putatively natural timeline of one's departure, they contend, not only goes against God's plan and the sacredness of life but it also short-circuits necessary processes of human struggle and leads to the shirking of "one's moral duties" (Callahan 2002, 56). In line with Catholic ideals that tie suffering to the prospect of redemption, the end-of-life ordeals faced by patients in their final days are seen to provide crucial opportunities for spiritual growth.

To be sure, arguments against aid-in-dying are not made exclusively on religious grounds, and there are Roman Catholic and Protestant theologians who have come out in favor of medically assisted death on the basis of the concept of neighborly love (Badham 2009; Jens and Küng 2009). And still, religious values tend to permeate even ostensibly secular opposition to assisted-dying laws through a new rhetoric that focuses on risk - the idea of suicide as a public health threat — which is increasingly supplanting the discourse around suicide as sin (Gandsman 2016). It is this sentiment that makes opponents question the seemingly incongruent in- 
volvement of the state in preventing suicides through public health interventions while at the same time encouraging them by sanctioning assisted deaths. A closer look at how the state administers these deaths reveals a more complex situation that does seek to distinguish between aid-in-dying and suicide.

\section{AUTHORIZING DEATH AND THE LIMITS OF AUTONOMY}

In states that have legalized medical aid-in-dying, the death certificate of individuals who avail themselves of these laws must list their underlying condition as the cause of death, making no mention of either aid-in-dying or suicide. Oregon's Death with Dignity Act also contains this telling passage: "Actions taken in accordance with [the Act] shall not, for any purpose, constitute suicide, assisted suicide, mercy killing or homicide, under the law." Legally, medical aid-in-dying is therefore not registered as suicide, reflecting an effort by the state to keep a categorical distinction between the two acts in place and to prevent life and health insurance companies from reneging on their policies. The power of this distinction does not, however, derive from the law alone. Rather, the law "defer[s] to the authority of medicine" (Lavi 2005, 89), which is incapable of navigating these novel frontiers on its own. As seen, too, in the creation of "brain death" as a new category of death in the 1960s by the Harvard Ad Hoc Committee (Lock 2002), such laws are called on to facilitate emergent social realities rooted in medical interventions.

One important consequence of the way Oregon's Death with Dignity Act was written - something that differentiates assisted-dying laws in the United States from those in Europe - is that medical professionals are charged with upholding a distinction between a medically aided death and suicide in their quotidian clinical work by screening for mental illness, especially depression, and with assessing whether it influences a patient's request for assisted dying. Physicians must weed out "suicidal" patients from those whose desire to end their life results legitimately from their terminal prognosis and who are thus authorized to die. If a physician suspects that a patient's motives for terminating their life exceed the condition of their illness, their case must undergo further scrutiny by a mental health expert. As Linda Ganzini, a prominent Oregon psychiatrist who has published extensively on medical aid-in-dying, told me: "We know that 60-70 percent of people who commit suicide have a mental disorder, particularly severe depression. If we treated the depression, they would make a different choice. . . But that's just a small subset of people who want physician aid-in-dying."

Ganzini readily acknowledges that the screening process for assisted dying is more complicated than the law would suggest, as those responsible for implement- 
ing the law try to evaluate what she calls the "authenticity" of a patient's decision to pursue an aided death, that is, whether their decision is consistent with their long-term coping strategies. Nick Gideonse, a physician and associate professor of family medicine in Portland, has developed his own mechanism for assessing possible psychiatric suicidality in a patient: "I will usually ask the question, 'If I had the magic wand, if we did tomorrow invent the curative aspect that could remove this cancer, this Lou Gehrig's disease from your life, would you still be pursuing this?' To me, that makes pretty clear what the driving force is."

Attending and consulting physicians are of course aware that a terminal diagnosis may cause a patient to experience painful realizations and profound sadness at the fact that their life is ending. In fact, some advocates maintain that the suicidal indicia used to diagnose depression should not be used for aid-in-dying applicants. "If you say to a person who is terminally ill, do you think about dying? Well, hell yes I think about dying, I'm dying," one advocate told me. To complicate things further, the side effects of a terminal illness such as cancer or its treatment - loss of appetite, fatigue, feelings of hopelessness, sleep irregularity — can look exactly like the telltale signs of a major depressive disorder. The challenge for physicians, then, is to determine whether any of these symptoms indicate a depression or another mental disorder, and whether these might be impairing a patient's judgment. As Grube explained:

You have to start with the fact that 100 percent of people who are about to die are grieving and sad. If they're happy that they're about to die, that's probably mental illness. But in major depressive disorder, generally it doesn't just show up willy-nilly when you get terminally ill. It's been going on for many years. ... If they've been on antidepressants before, that makes me sit up a little straighter and ask harder questions. But if they're really sad because they got liver cancer, wow, that's - they should be. It's horrible.

In other words, signs of depression need not, in and of themselves, raise questions about a patient's ability to make an informed decision or render them otherwise incompetent. But patients have to be capable of grasping the consequences of their actions and show evidence of being cognitively intact. They must repeat what they are asking for at multiple stages during the application process, and often right until they take the medication. In fact, the written request that patients complete ends with the line: "I make this request voluntarily and without reservation, and I accept full moral responsibility for my actions," thus placing final responsibility for the act back onto the patient. 
At first glance, the language of informed consent and accountability seems to signify the epitome of a world in which self-optimizing, responsible subjects decide on the manner of their own demise. Aid-in-dying requires patients to select an assisted death as an act of rational choice. Self-acting citizen-subjects - in consultation with their physicians - are seemingly not just taking private charge of their health and well-being (Rose 2007) but are also judiciously choosing the manner of their own dying, eluding the state's control over death.

And yet, in practice, not only is this choice heavily circumscribed by the patient's already terminal condition but the agency for their death also rests in large part with the state and with physicians as organs of the state. Patients who avail themselves of aided dying operate squarely within bureaucratic regulations of what constitutes an authorized death - they must demonstrate that their desire to end their life falls strictly within the limits set by the state. To qualify for Oregon's Death with Dignity Act, a mentally sound adult must have a terminal prognosis of less than six months to live; must be an Oregon resident; must have made one written and two oral requests separated by fifteen days; must be able to self-administer the lethal drugs; and must have been independently assessed by two physicians. ${ }^{14}$ The law thus tightly structures the process through which a specific group of patients already deemed to be dying may end their life. Especially in rural parts of Oregon east of the Cascades and on the coast, patients struggle to find two physicians who will approve their request (or even just enter it into their medical record), particularly as many hospitals there are owned by Catholic health systems that bar their clinicians from participating in the law (Bannow 2017). Between 1998 and the start of 2018, a total of 1,275 patients ended their lives under Oregon's Death with Dignity Act.

Even if political power in the West concerns itself principally with the administration of life today (Foucault 1978), the state retains a substantial hold over death via elaborate regulatory mechanisms and bureaucratic hurdles (see Bernstein 2016). In fact, nowadays the law folds the very principle of autonomy directly into a regime of regulation. "From this perspective," Lavi $(2005,167)$ contends, "autonomy is a more sophisticated way of regulating end-of-life decision making. . . . [The Death with Dignity Act] does not use coercion to impose a regulatory regime on the dying but rather makes use of autonomy to enhance the power of regulation." As a result, the purity of the desire to die comes under scrutiny by the state, compelling patients to reproduce the proper narratives at the proper time. As Dominique Memmi $(2003,655)$ points out: "The historical increase of 'self-determination' works through highly unusual avowal procedures: namely, the request 
made to social actors to subscribe solely to narratives that can be legitimated by the state." Indeed, if it becomes clear that a patient's motivation for seeking aidin-dying resides outside the limited scope of the law or is propelled by an ulterior desire to die, their ability to exercise that right can quickly be taken away.

In practice, physicians rarely encounter patients whose desire to die is divorced from or independent of their terminal condition - in 2016, Oregon doctors made use of the law's referral clause only 2.5 percent of the time (for 5 out of 204 patients who received prescriptions that year). But when they do, it can leave them deeply conflicted. Charles Blanke, a physician who heads a research unit on cancer in Portland, recounted the case of a patient who had an incurable form of cancer and who did fall within the six-month prognosis that qualified him for aid-in-dying, but whose reasons for wanting to end his life were less conventional:

He had six months, but he probably had a good four months of quality time, and I asked - because the state asked me to ask - "Why are you interested?" And he said: "I don't have any friends. I don't have any real quality of life — not because I'm ill, but for social-economic reasons." That one was a little challenging to me, because how is that different from someone who's just sad and wants to commit suicide? Except that he technically qualifies for the law. So that one was challenging. I don't see that very often.

Blanke referred this patient to a psychiatrist for evaluation who determined that he was competent and not depressed. "Or, if he was depressed, it wasn't affecting his competency," Blanke added. In the end, he agreed to write the prescription. His case crystallizes a central tension faced by administrators of aid-in-dying laws: what constitutes a legitimate reason to die and who has the authority to decide that? Within the parameters of the law, one doctor may agree that a patient's desire to end their life is valid, whereas another might not. For Blanke, a patient's self-determination routinely outweighed his impulse for medical paternalism. "I don't really feel it's my job to judge the quality of their reason," he explained. "My job as an oncologist is to outline the choices, the pluses, and the minuses, the risks, and the benefits, and help in finding the best choice for themselves." While some of his colleagues would try to coax patients into receiving all the treatments they could right until the end, he never felt it was his place to do so.

In fact, belief in a patient's right for self-determination - the ability to author one's own dying in the face of impending death — was the single most noticeable quality that prescribing physicians I have met during my research shared. Contrary 
to colleagues whose primary goal was to prolong or to ease a patient's life and who refused to administer the law, these doctors championed patient autonomy. Yet they all recognized limits to this kind of autonomy. Grube once shared with me the case of a patient who had been diagnosed with diabetes and who declined to take insulin, as he did not want to face the difficulty of living as a diabetic. He asked Grube if he could qualify for aid-in-dying. Because diabetes is considered a chronic but not inevitably lethal condition in the United States, Grube replied: "You're not acting kind of appropriately. I'm not going to participate with you in this. My professional integrity rises above your autonomy."

While this case might appear straightforward, a young adult patient refusing chemotherapy for lymphoma for fear of toxicity presents a much tougher call. Without treatment, the patient qualifies for the law, but with treatment she might live for another fifty years. "So the question is, do you offer this patient Death with Dignity?" Blanke, who consulted with the patient on her request, wanted to know. "And I will tell you, a lot of my colleagues — even those who support Death with Dignity_ say: 'No chance whatsoever. Why does she want to die? This is suicide. This isn't medically aided dying.' But the fact is, under the law it's not suicide." Hers was another case that the doctor referred for psychiatric consultation, which determined that she was fully competent and understood what she was doing.

In the United States, patients have had the right to refuse life-prolonging treatment since 1991, with the enactment of the federal Patient Self-Determination Act. Doctors do not have to agree with the reasoning behind a patient's decision to decline care, but they do have to ensure that patients are mentally capable of making it. Similarly, in trying to assess who among their aid-in-dying patients is motivated by circumstances outside the intent of the Death with Dignity Act, physicians are attempting to apply the state's distinction between medical aid-in-dying and a suicidal act - a line that can prove ambiguous for some.

For a form of death routinely portrayed as the ultimate manifestation of free will, assisted dying hinges fundamentally on the authorizing power of both medicine and the state. Without such endorsement or regulatory oversight, a patient's wish to end their life threatens to run into the sand. In contrast to suicide, medically assisted deaths allow the state to retain control over who may die and under what circumstances. The state-through its medical professionals - thus preserves the right to determine who gets to opt out of life and to differentiate between a moral and an immoral death. It is precisely the involvement of physicians and state authorities that lends medically assisted deaths a significant measure of social and moral legitimacy — a quality notably absent in popular understandings of suicide 
and in cases where terminally ill people use "do-it-yourself" methods to end their own lives (Richards 2017).

\section{AUTHORING DEATH}

If there is one aspect of assisted dying that seems clearly to reinstate the agentive involvement of the patient, it is the potential for a good death the practice affords, in contrast to either the diminishment wrought by the end of debilitating illness or the classically bad death of suicide. As Maurice Bloch and Jonathan Parry (1982, 16-18) note, in many cultures suicide signifies the "supreme example of 'bad' death," as it occurs both at the wrong time and the wrong place and condemns death to the "disorganized wild." Margaret Lock (2002, 195), too, writes that it is precisely the uncontrolled and sudden nature of suicides that "produces profound feelings of disorder in those 'left behind,"' as in the testimony of Pauline Mars, mentioned above. By contrast, advocates position medically aided deaths as tender, orderly, and communal affairs that are usually arranged in advance, staged at home, and carried out with the help of many others in the know. ${ }^{15}$ As Peter Reagan, the first Oregon physician whose prescription of a lethal dose of barbiturates led to a patient's death in 1998, said to me: "If you're talking to your family and inviting them to your death and then taking a medicine in the presence of other people, it's — it's a whole different thing!”

In preparing for an assisted death, patients and families try to realize their own version of a good death - frequently, a quiet (but occasionally festive) home death enacted in front of a privileged audience of loved ones, usually family and sometimes friends. In fact, it is precisely the medical management of aided deaths that allows participants to lay claim to ideas about authorship because of their ability to time and shape such a death and to imbue it with purpose.

Derianna Mooney, a volunteer for End of Life Choices Oregon - an organization that accompanies patients and families on their path to an assisted death - has witnessed hundreds of planned deaths. A vivacious retired nurse in her seventies, she drives across Oregon and Washington to be with patients during their final hours. To her, a good death is one where everyone who wants to be present has assembled at the bedside, feels prepared, and has reached a level of acceptance: “They're grieving, they're horribly grieving, but they are so grateful to be there. It's something that everybody is doing together. To watch someone die, in front of you, I think is not as hard as what your mind does if they die away from you. It's a ritual of witnessing." During one of our talks, Mooney brought up the idea of "loving someone out," referring to all the words and actions family and friends deploy to 
lift someone over the threshold between life and death. "You're going to the gate with them and letting them go," she said, "but you're nurturing them through the gate." To illustrate, she mentioned the case of one patient whose entire family had at first opposed her desire for an aided death, but who eventually came together to see her off:

And then when she died, she had a wig on - she had her hair all done up in this beautiful wig — she had this beautiful little blue jumpsuit on with jewelry and her nails done. We tell them this is awful-tasting medicine but you only have to do it once and you have to drink it in ninety seconds or less. So she took a sip of it [and said]: "Oh! That's horrible!” And then the whole family, there were five kids there and her husband and her best friend, [they shouted] "Drink, drink, drink!" They were chanting her out!

Of course, family members and significant others do not always agree on the goodness of an assisted death; some have religious objections in principle to the practice, others feel regret that their loved one is dying earlier than they might otherwise, or they are in denial about their impending demise. And yet those close to a patient often put aside their personal objections to support the patient's request in what Robb Miller - a longtime advocate for end-of-life choices who lives in Seattle - calls "loyal opposition." "They will remain opposed to it, but they will not interfere," he told me. "That's as far as some people can get. . . . [If they are not present] their loved one might feel abandoned by them, and they might ultimately feel they abandoned their loved one in retrospect." Nonetheless, the social, relational element of dying can make it difficult to predict how those left behind will evaluate a death after the fact and whether they will ever describe it as "good."

In giving death a new script, an assisted death removes many uncertainties of how, when, and where someone will die, allowing patients to try to mend bridges, plan for a particular kind of departure, and reach closure with family members opportunities often unavailable to those who die suddenly and unexpectedly. Linda Jensen, also a volunteer for End of Life Choices Oregon, is convinced that most patients opt for an assisted death primarily for the sake of their family. "That's the gift these people give to their families," she explained to me. "They don't hold the mental picture of a loved one in pain or gasping for air or all those things that happen when people die certain kinds of death." Of course, idealized visions of a good death do not always become a reality. While an aided death seldom involves writhing, incontinence, or seizures, there are accounts of patients choking on or 
regurgitating some of their medication or, in some rare cases, waking up again hours later. Still, the perceived authorship afforded by an assisted death comes very close to advocates' ideal of dying well.

\section{CONCLUSION}

We are witnesses to a moment in which the cultural authority and reach of medicine, in concert with the law, are rewriting not just the ways North Americans die - a process that started long ago- but also moralities of dying more broadly. We must therefore take stock of the powerful ability of medicine-as a form of biopolitical governance - to transform the very categories of human existence. When medicine can no longer prolong life, it is called on to facilitate a good death, evidenced by the emergence of the hospice movement, palliative care, and, more recently, assisted-dying regimes. The involvement of medicine in requested deaths has not only augmented their moral legitimacy; it has also led to the construction of a new kind of death that departs in key ways from existing forms of purposive death. For proponents, a medically aided death hinges on a particular relationship between life-limiting illness, agency, and finality that contrasts sharply with the received logic of suicide and that warrants a moral and conceptual category of its own.

Other sites at which moralities of dying are being reshaped by medicine and the state range from the ongoing abortion controversy (where it is yet unclear if a medical model will prevail) to changing (medical) scripts for the administration of capital punishment to advance directives (or "living wills"). Acrimonious discussions around expanding the stipulations of advance directives to include provisions for patients with dementia to opt out of being spoon-fed show how contested ideas of human agency, rationality, and responsibility remain when it comes to matters of living and dying. Currently, living wills cover only medical interventionssuch as artificial nutrition through a feeding tube - but not processes of regular nourishment. Bill Harris, a resident of southern Oregon, learned this the hard way when he sued the memory care facility that persisted in spoon-feeding his wife Nora, whose Alzheimer's had progressed so far that she lost all ability for self-expression and feeding. Despite having recorded in her advance directive years ago that she did not want to prolong the process of her illness, such as through assisted feeding, her request was deemed invalid. On the form, Bill and Nora had mistaken the term "parenteral feeding" (which means feeding through an IV) for "parental feeding." Nora thought she had agreed to cease all spoon-feeding when she could no longer feed herself. Yet such an option had never been on the table. Here, as in 
assisted death, the tension between authorship and authorization comes into relief once more as dying patients and their loved ones try to navigate the medico-legal landscape of end-of-life decisions, where human agency remains as diffuse as it does disputed.

\begin{abstract}
In 2017, Oregon marked the twentieth anniversary of enacting the Death with Dignity Act, allowing terminally ill, mentally competent adult patients to end their life by ingesting a lethal medication prescribed by their physician. In U.S. public discourse, medical aid-in-dying is frequently equated with the terminology and morality of suicide, much to the frustration of those who use and administer the law. This article reflects on the stakes of maintaining a distinction between a medically assisted death and the most common cultural category for self-inflicted death-suicide. It uncovers the complicated dialectic between authorship and authorization that characterizes medical assistance in dying and attendant moralities of purposive death, speaking to broader disciplinary concerns in the cultural study of death and medicine. By stressing the primacy of debilitating, life-limiting illness in an aided death and by submitting such a death to the rationale and management of institutionalized medicine, advocates carve out a form of intentional death that occupies a category of its own. The diffusion of agency onto a patient's fatal illness, medicine, and the state - both discursively and in practice - enhances the moral and social acceptability of an assisted death, which becomes an authorized form of dying that looks very different from the socially deviant act of suicide. [medical aid-in-dying; suicide; agency; rationality; death; medicine; United States]
\end{abstract}

\title{
NOTES
}

Acknowledgments This article benefited from the generous input of numerous readers and interlocutors. Primary among them are colleagues and students at Brandeis University, Tulane University, the University of Leipzig, Reed College, and Portland State University. George Paul Meiu and Ilana Cohen read earlier versions and provided vital insights. I am thankful, too, for the detailed and productive feedback of the anonymous reviewers and to the editors of $\mathrm{Cul}$ tural Anthropology, who expertly guided this process. Special thanks go to Heather Paxson, whose discerning editorial suggestions helped massage the manuscript into its final form. I am grateful to my research assistants (Doug Bafford, Ilana Cohen, Alyssa Martin, Sierra Dakin Kuiper, and Amanda Votta) for their diligence with the interview transcriptions. Lastly, I am profoundly indebted to my research subjects for their time and expertise, and for trusting me with their stories.

1. The full statement, entitled “'Suicide' Is Not the Same as 'Physician Aid in Dying," can be found at https://www.suicidology.org/statements.

2. Honoring the wishes of my interlocutors, I do not utilize pseudonyms in this article, but I do occasionally omit someone's name for privacy reasons. All interviewees reviewed and approved their quotations.

3. In 1994, Oregon became the first U.S. state to legalize aid-in-dying. Washington (2008), Vermont (2013), California (2015), Colorado (2016), the District of Columbia (2017), and Hawaii (2018) followed suit. In Montana, the state decriminalized aid-in-dying in 
2009 through a Montana Supreme Court ruling, but it never formally codified the practice.

4. For example, Paul Bohannan's (1960) edited volume on African Homicide and Suicide shows that, in most instances, suicide is not considered a fully volitional act as it depends on the intercession of various supernatural forces.

5. This tension is evident in the literature on rational suicide, which asks whether suicide under certain circumstances - such as old age or terminal illness - can be rational and thus moral, following the Kantian equation of rationality with morality (Werth 1999; McCue and Balasubramaniam 2017). While valuable, this literature does not tend to examine the usefulness of the category of suicide as such, but takes its internal cohesion for granted.

6. For a discussion of the right-to-die language around dignity, see Gandsman and Burnier 2014.

7. A minority of proponents, among them Derek Humphry, the founder of the Hemlock Society, continued using the rhetoric of suicide after most right-to-die activists had abandoned it, arguing that calling a medically aided death anything but suicide was euphemistic.

8. This interview was conducted by Matthew E. Simek as part of a project by the Oregon Health and Science University Oral History Program on June 4, 2008. In 2012, Goodwin used the Death with Dignity Act himself, after being diagnosed with a rare neurodegenerative disease.

9. In 2017, 91 percent of patients who used the Death with Dignity Act were on hospice, meaning that theirs was not an either-or decision.

10. See https://www.canada.ca/en/health-canada/services/publications/health-systemservices/medical-assistance-dying-interim-report-sep-2017.html for the full report.

11. There is a wide spectrum of positions among proponents and dissidents of assisted-dying laws in the United States. My use of such descriptors as advocate or opponent is not meant to deny this complexity but to identify common positions held by those I encountered during my research.

12. As they became cognizant of its alienating effect on members of the hospice community, practitioners dropped the term hastening. Most hospices conceive of their mission as neither prolonging life nor hastening death.

13. For example, the websites of two major right-to-die organizations in the United StatesCompassion and Choices and the Death with Dignity National Center-foreground the language of rights and choices.

14. Oregon's Death with Dignity Act (and similar statutes elsewhere in the United States) is the most restrictive assisted-dying law in the world. Countries such as Belgium, the Netherlands, and Canada allow for more open-ended prognoses that include various degenerative conditions and, in some cases, psychological suffering. All three countries also offer the possibility of a lethal injection in lieu of self-administration.

15. There are, of course, suicides that are elaborately ritualized, meticulously planned, and also collective. Many of these deaths, however, are often regarded not as suicides, but as acts of martyrdom (Nanninga 2016).

\section{REFERENCES}

Asad, Talal

2007 On Suicide Bombing. New York: Columbia University Press.

Badham, Paul

2009 Is There a Christian Case for Assisted Dying? Voluntary Euthanasia Reassessed. London: Society for Promoting Christian Knowledge.

Bannow, Tara

2017 "Rural Oregonians Still Face Death with Dignity Barriers: Roadblocks Abound in Rural Areas." Bend Bulletin, August 14. https://www.bendbulletin.com/ health/5512373-151/rural-oregonians-still-face-death-with-dignity-barriers. 
Bernstein, Anya

2016 "Love and Resurrection: Remaking Life and Death in Contemporary Russia." American Anthropologist 118, no. 1: 12-23. https://doi.org/10.1111/aman.12445.

Bloch, Maurice, and Jonathan Parry

1982 "Introduction: Death and the Regeneration of Life." In Death and the Regeneration of Life, edited by Maurice Bloch and Jonathan Parry, 1-44. New York: Cambridge

Bohannan, Paul, ed. University Press.

Callahan, Daniel

1960 African Homicide and Suicide. Princeton, N.J.: Princeton University Press.

2002 “Reason, Self-Determination, and Physician-Assisted Suicide." In The Case against Assisted Suicide: For the Right to End-of-Life Care, edited by Kathleen Foley and Herbert Hendin, 52-68. Baltimore: Johns Hopkins University Press.

Cauchon, Dennis, and Martha Moore

2002 "Desperation Forced a Horrific Decision." USA Today, September 2. https:// usatoday30.usatoday.com/news/sept11/2002-09-02-jumper_x.htm.

Douglas, Jack D.

1967 The Social Meanings of Suicide. Princeton, N.J.: Princeton University Press.

Durkheim, Émile

1951 Suicide: A Study in Sociology. Translated by John A. Spaulding and George Simpson. New York: Free Press. Originally published in 1897.

Foucault, Michel

1978 The History of Sexuality, Volume 1: An Introduction. Translated by Robert Hurley. New York: Random House. Originally published in 1976.

Gandsman, Ari

2016 “'A Recipe for Elder Abuse:' From Sin to Risk in Anti-Euthanasia Activism.” Death Studies 40, no. 9: 578-88. https:/ / doi.org/10.1080/07481187.2016.1193568.

2017 "The Paradox of Choice and the Illusion of Autonomy: The Construction of Ethical Subjects in Right-to-Die Activism.” Death Studies 42, no. 5: 329-35. https://doi. org/10.1080/07481187.2017.1396646.

Gandsman, Ari, and Daniel Burnier

2014 “'Can't you at least die with a little dignity?' The Right to Die Debates and Normative Dignity.” BioéthiqueOnline 3/8. http:/ / hdl.handle.net/1866/10945.

Garcia, Angela

2010 The Pastoral Clinic: Addiction and Dispossession along the Rio Grande. Berkeley: University of California Press.

Golden, Marilyn, and Tyler Zoanni

2010 "Killing Us Softly: The Dangers of Legalizing Assisted Suicide." Disability and Health Journal 3, no. 1: 16-30. https://doi.org/10.1016/j.dhjo.2009.08.006.

Hacking, Ian

2008 “The Suicide Weapon.” Critical Inquiry 35, no. 1: 1-32. https:/ / doi.org/10.1086/ 595626.

Halbwachs, Maurice

1978 The Causes of Suicide. Translated by Harold Goldblatt. New York: Free Press.

Jens, Walter, and Hans Küng

2009 Menschenwürdig sterben — ein Plädoyer für Selbstverantwortung. Munich: Piper.

Karsoho, Hadi, Jennifer R. Fishman, David Kenneth Wright, and Mary Ellen Macdonald

2016 "Suffering and Medicalization at the End of Life: The Case of Physician-Assisted Dying." Social Science and Medicine 170: 188-96. https://doi.org/10.1016/j.

Kaufman, Sharon R. socscimed.2016.10.010.

2005 And a Time to Die: How American Hospitals Shape the End of Life. Chicago: University of Chicago Press. 
Lavi, Shai J.

2005 The Modern Art of Dying:A History of Euthanasia in the United States. Princeton, N.J.: Princeton University Press.

Livingston, Julie

2009 "Suicide, Risk, and Investment in the Heart of the African Miracle." Cultural Anthropology 24, no. 4: 652-80. https://doi.org/10.1111/j.1548-1360.2009. 01043.x.

Lock, Margaret

2002 Twice Dead: Organ Transplants and the Reinvention of Death. Berkeley: University of California Press.

Lopes, Giza

2015 Dying with Dignity: A Legal Approach to Assisted Death. Santa Barbara, Calif.: Praeger.

Mahmood, Saba

2001 "Feminist Theory, Embodiment, and the Docile Agent: Some Reflections on the Egyptian Islamic Revival.” Cultural Anthropology 16, no. 2: 202-236. https://doi. org/10.1525/can.2001.16.2.202.

McCue, Robert E., and Meera Balasubramaniam, eds.

2017 Rational Suicide in the Elderly: Clinical, Ethical, and Sociocultural Aspects. New York: Springer.

Memmi, Dominique

2003 "Governing through Speech: The New State Administration of Bodies." Translated by Susan Taponier. Social Research 70, no. 2: 645-58. https://muse.jhu.edu/ article/558581.

Münster, Daniel, and Ludek Broz

2015 "The Anthropology of Suicide: Ethnography and the Tension of Agency." In Suicide and Agency: Anthropological Perspectives on Self-Destruction, Personhood, and Power, edited by Ludek Broz and Daniel Münster, 3-23. Burlington, Vt.: Ashgate.

Nanninga, Pieter

2016 “The Liminality of 'Living Martyrdom:' Suicide Bombers' Preparations for Paradise." In Ultimate Ambiguities: Investigating Death and Liminality, edited by Peter Berger and Justin Kroesen, 79-96. New York: Berghahn.

Pernick, Martin S.

1985 A Calculus of Suffering: Pain, Professionalism, and Anesthesia in Nineteenth-Century America. New York: Columbia University Press.

Richards, Naomi

2017 "Assisted Suicide as a Remedy for Suffering? The End-of-Life Preferences of British 'SuicideTourists." MedicalAnthropology 36,no.4:348-62.https://doi.org/10.1080/ 01459740.2016.1255610.

Rose, Nikolas

2007 The Politics of Life Itself: Biomedicine, Power, and Subjectivity in the Twenty-First Century. Princeton, N.J.: Princeton University Press.

Schotsmans, Paul T.

2003 "Relational Responsibility, and Not Only Stewardship. A Roman Catholic View on Voluntary Euthanasia for Dying and Non-Dying Patients." Christian Bioethics 9, nos. 2-3: 285-98. https://doi.org/10.1093/chbi.9.2.285.30288.

Werth, James L., Jr., ed.

1999 Contemporary Perspectives on Rational Suicide. Philadelphia: Brunner/Mazel.

Willerslev, Rane

2009 "The Optimal Sacrifice: A Study of Voluntary Death among the Siberian Chukchi." American Ethnologist 36, no. 4: 693-704. https://doi.org/10.1111/j.15481425.2009.01204.x. 